\title{
Bulk-Heterojunction Organic Solar Cells Based on Benzobisthiadiazole Semiconducting Polymers
}

\author{
Yang Wang ${ }^{1}$, Michael F. G. Klein ${ }^{2}$, Junya Hiyoshi ${ }^{1}$, Susumu Kawauchi ${ }^{1}$, \\ Wallace W. H. Wong ${ }^{2}$, and Tsuyoshi Michinobu ${ }^{1}$ \\ 1 Department of Organic and Polymeric Materials, Tokyo Institute of \\ Technology, 2-12-1 Ookayama, Meguro-ku, Tokyo 152-8552, Japan. \\ *michinobu.t.aa@m.titech.ac.jp (TM) \\ 2 School of Chemistry, Bio21 Institute, The University of Melbourne, \\ 30 Flemmington Road, Parkville, Victoria, 3010, Australia. \\ *wwhwong@unimelb.edu.au (WWHW)
}

\begin{abstract}
Benzobisthiadiazole (BBT)-containing donor-acceptor polymers were investigated as semiconductors in bulk-heterojunction organic solar cells. Taking advantage of the polarity change of the BBT-based copolymers in terms of comonomer structures, they were examined as both p-type and n-type semiconductors. In the case of n-type semiconductors, fullerene-free organic solar cells were fabricated. A power conversion efficiency (PCE) of $0.02 \%$ was achieved when fluorenyl hexa-peri-hexabenzocoronene (FHBC) was employed as a p-type semiconductor. The limited performance might be due to the strong intermolecular $\pi-\pi$ stacking of BBT-based copolymers, resulting in the poor miscibility between the donor molecule and acceptor polymer.
\end{abstract}

Keyword: benzobisthiadiazole, organic solar cells, semiconducting polymers

\section{Introduction}

With the aim of environment-friendly and cost-effective conversion of solar energy to clean electricity, solution-processable bulk-heterojunction (BHJ) polymer solar cells (PSCs) have been intensively researched as the technology offers the possibility of low-cost, light-weight, and flexible devices [1]. Benefiting from the newly designed high-performance p-type semiconducting polymers, PSCs have seen a dramatic increase in the power conversion efficiencies (PCEs) up to $9-10 \%$ over the last five years [2]. However, the development of the competing n-type semiconducting polymers has lagged far behind. This is partly because fullerene derivatives, such as $\mathrm{PC}_{61} \mathrm{BM}$ ([6,6]-phenylC61-butyric acid methyl ester) and $\mathrm{PC}_{71} \mathrm{BM}$ ([6,6]-phenyl-C71-butyric acid methyl ester), have been the excellent n-type semiconductors in
BHJ-PSCs due to their high electron mobility and charge separation properties. However, there are also limitations in the fullerene derivatives, that are weak absorption in the near-infrared (NIR) spectral region and tedious purification processes in their syntheses.

In order to overcome the shortcomings of the fullerene derivatives, considerable efforts have recently been dedicated to the development of non-fullerene acceptors [3]. As a consequence, fullerene-free PSCs appeared as emerging photovoltaic devices, and their PCEs have already reached 5-7\% [4]. However, non-fullerene acceptors are still in their infancy.

Benzobisthiadiazole (BBT) is a strong electron-accepting building block composed of a $14 \pi$-electron system. It is expected that the BBT-containing conjugated polymers are good n-type semiconductors. Due to the planar 
triple-fused-ring structure of BBT, the BBT polymers often show high crystallinity ascribed to the effective interchain $\pi-\pi$ overlaps. In general, crystalline organic semiconductors display better intermolecular charge transport as compared to the amorphous semiconductors. For example, a high hole mobility up to $2.5 \mathrm{~cm}^{2} \mathrm{~V}^{-1} \mathrm{~s}^{-1}$ and an electron mobility up to $1.36 \mathrm{~cm}^{2} \mathrm{~V}^{-1} \mathrm{~s}^{-1}$ have been realized in organic field effect transistors (OFETs) based on the BBT copolymers [5]. However, only a limited number of BBT polymers have been reported in PSCs [6]. In this paper, we applied three BBT-based copolymers, namely PBBT-FT, PBBT-T-FT, and PBBT-Tz-FT, to BHJ organic solar cells. In addition to the conventional PSCs based on polymer/PCBM mixtures, the BBT-based copolymers were, to the best of our knowledge, for the first time employed as n-type semiconductors in PSCs (Figure 1). Fluorenyl hexa-perihexabenzocoronene (FHBC) [7], 3,6-bis[5(benzofuran-2-yl)thiophen-2-yl]-2,5-bis(2-(2-(2-m ethoxyethoxy)ethoxy)ethyl)pyrrolo[3,4-c]pyrrole-1 ,4-dione $\left[\mathrm{DPP}(\mathrm{TBFu})_{2}\right] \quad[8]$, and poly[4,8bis(5-(2-ethylhexyl)-4-hexylthiophen-2-yl)-benzo[ 1,2-b:4,5-b']dithiophene-benzothiadiazole] (CP3) [9] were selected as donor materials (p-type semiconductors) from the list of our previous studies (Univ. Melbourne group). UV-vis-NIR absorption, energy levels, and photovoltaic properties were described.

\section{Experimental}

\subsection{Materials}

PBBT-FT, PBBT-T-FT, PBBT-Tz-FT, FHBC, $\operatorname{DPP}(\mathrm{TBFu})_{2}$, and CP3 $\left(\mathrm{M}_{\mathrm{w}}=210 \mathrm{~kg} \mathrm{~mol}^{-1}, \mathrm{M}_{\mathrm{n}}=\right.$
$67 \mathrm{~kg} \mathrm{~mol}^{-1}$ ) were synthesized according to the literatures [7-10]. Other reagents and solvents were purchased as analytical-grade quality and used without further purification.

\subsection{Measurements}

UV-vis-NIR spectra were recorded on a JASCO V-670 spectrophotometer. Electrochemistry measurements were carried out on a BAS electrochemical analyzer model $612 \mathrm{C}$ at $25{ }^{\circ} \mathrm{C}$ in a classical three-electrode cell. The working, reference, and auxiliary electrodes were a glassy carbon electrode, $\mathrm{Ag} / \mathrm{AgCl} /$ $\mathrm{CH}_{3} \mathrm{CN} /\left(n \mathrm{C}_{4} \mathrm{H}_{9}\right)_{4} \mathrm{NPF}_{6}$, and a Pt wire, respectively. The polymer films for electrochemical measurements were coated from a chloroform solution (ca. $5 \mathrm{~g} \mathrm{~L}^{-1}$ ). For calibration, the redox potential of ferrocene/ferrocenium $\left(\mathrm{Fc} / \mathrm{Fc}^{+}\right)$was measured under the same conditions, and it was located at $0.09 \mathrm{~V} v s$ the $\mathrm{Ag} / \mathrm{AgCl}$ electrode. It was assumed that the redox potential of $\mathrm{Fc} / \mathrm{Fc}^{+}$has an absolute energy level of $-4.80 \mathrm{eV}$ to vacuum. The HOMO and LUMO energy levels were then calculated according to the following equations:

$$
\begin{aligned}
& \mathrm{E}_{\text {HOMO }}=-\left(\varphi_{\mathrm{ox}}+4.71\right)(\mathrm{eV}) \\
& \mathrm{E}_{\mathrm{LUMO}}=-\left(\varphi_{\mathrm{re}}+4.71\right)(\mathrm{eV})
\end{aligned}
$$

where $\varphi_{o x}$ is the onset oxidation potential vs $\mathrm{Ag} / \mathrm{AgCl}$ and $\varphi_{\text {re }}$ is the onset reduction potential $v s$ $\mathrm{Ag} / \mathrm{AgCl}$.

2.3. Fabrication and characterization of BHJ-PSCs All photovoltaic devices had a conventional

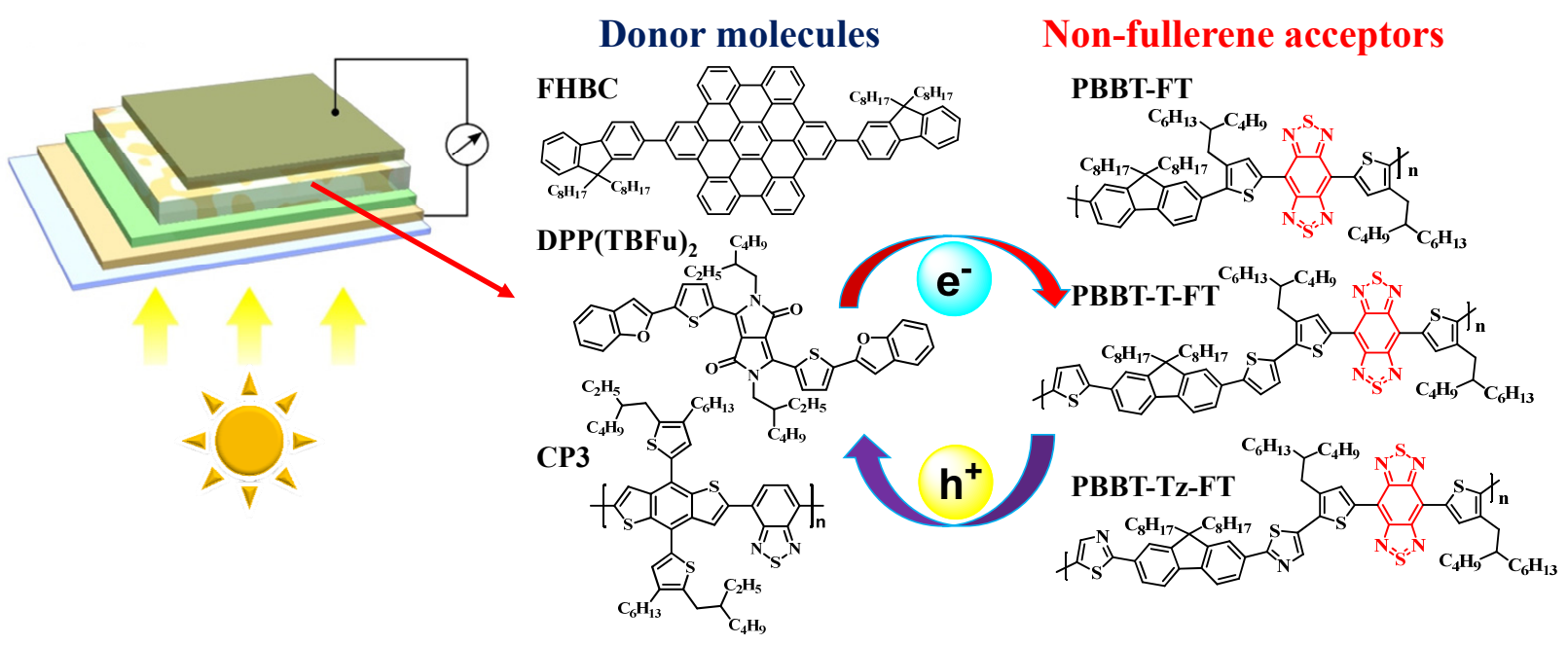

Figure 1 Schematic illustration of the photovoltaic device and the semiconducting materials of donor molecules and non-fullerene acceptors explored in this study. 


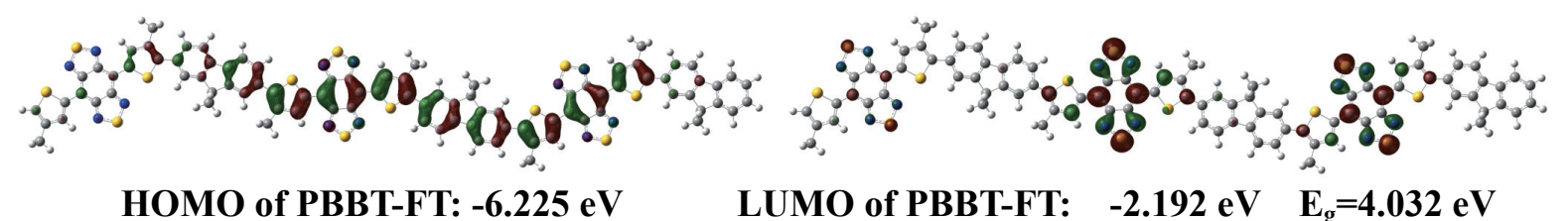

HOMO of PBBT-FT: $-6.225 \mathrm{eV}$

LUMO of PBBT-FT: $\quad-2.192 \mathrm{eV} \quad \mathrm{E}_{\mathrm{g}}=4.032 \mathrm{eV}$

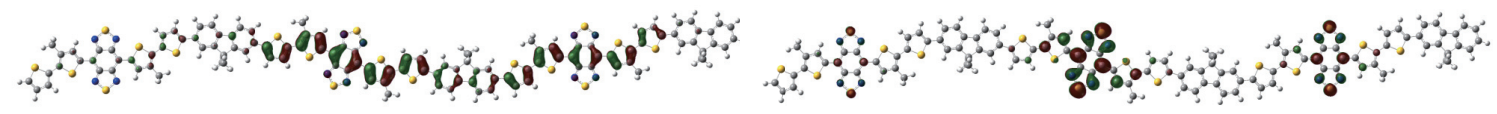

HOMO of PBBT-T-FT: $-6.233 \mathrm{eV}$

LUMO of PBBT-T-FT: $-2.233 \mathrm{eV} \quad \mathbf{E}_{\mathrm{g}}=4.000 \mathrm{eV}$

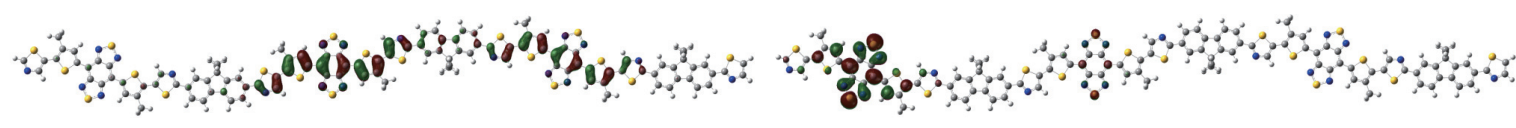

HOMO of PBBT-Tz-FT: -6.473 eV LUMO of PBBT-Tz-FT: $-2.348 \mathrm{eV} \quad \mathrm{E}_{\mathrm{g}}=4.125 \mathrm{eV}$

Figure 2. Wave functions of the HOMO and LUMO orbitals of the model trimers calculated at the level of $\omega B 97 X-D / 6-31 G(d, p)$.

device architecture, ITO/PEDOT:PSS/ p-,nsemiconductors/LiF/A1/Ag. ITO-coated glass substrates were ultrasonically cleaned sequentially in detergent, water, acetone, and isopropanol (IPA), followed by the treatment in an ultraviolet ozone chamber. The cleaned substrates were covered by an approximately $25 \mathrm{~nm}$ thick layer of PEDOT:PSS (Baytron PV PAI 4083, Germany) by spin-coating. BBT-based copolymers were dissolved in 1,2-dichlorobenzene (DCB), and then counter semiconductors (PCBM or donor molecules) were added. After the solution was heated to $100{ }^{\circ} \mathrm{C}$ and stirred overnight at the same temperature, it was spin-coated to form the active layer at $1200 \mathrm{rpm}$ for $40 \mathrm{~s}$. The cathode made of LiF, aluminium, and silver was sequentially evaporated through a shadow mask under high vacuum $\left(<10^{-6}\right.$ Torr $)$. The device characteristics were evaluated using a Xenon lamp at AM1.5 solar illumination (Oriel Instruments). The current-voltage $(\mathrm{J}-\mathrm{V})$ characterization of the devices was carried out on a computer-controlled Keithley 2440 Source Measurement system.

\section{Results and Discussion}

3.1 Optical and electrochemical properties

All BBT-based copolymers showed similar absorption spectra with two absorption bands (Band I: 600-1200 nm; Band II: 300-600 nm) and narrow band gaps of around 1.0 1.1 eV (Table 1). The details of the UV-vis-NIR absorption spectra are found in the previous work (Tokyo Inst. Tech. group) [10]. It should be noted that the broad absorption bands $(300-1200 \mathrm{~nm})$ are suitable for the active layer of PSCs.
The highest occupied molecule orbital (HOMO) and the lowest unoccupied molecule orbital (LUMO) energy levels were firstly estimated by density functional theory (DFT) calculations. The DFT calculations of the model trimers were performed using the $\omega \mathrm{B} 97 \mathrm{X}-\mathrm{D} / 6-31 \mathrm{G}(\mathrm{d}, \mathrm{p})$ method. Instead of the long alkyl chains, methyl groups were used to shorten the calculation time. The calculated molecular orbitals (MOs) and Frontier orbital energies are shown in Figure 2. For all the three models, the electron densities of the HOMO were delocalized over both the donor and acceptor units, whereas those of the LUMO were primarily located on the BBT unit. This electronic distribution is commonly observed for donor-acceptor alternating copolymers, which show a pronounced intramolecular charge transfer. Although the absolute values of $\mathrm{E}_{\mathrm{HOMO}}$ and $\mathrm{E}_{\mathrm{LUMO}}$ were far from the authentic values, the order of the bandgap narrowing of PBBT-Tz-FT> PBBT-FT $>$ PBBT-T-FT agreed with that determined by electrochemical measurements (vide infra).

Table 1. Optical and electrochemical properties of the BBT polymers

\begin{tabular}{lccccc}
\hline & $\begin{array}{l}\lambda_{\text {onset }} \\
(\mathrm{nm})^{\mathrm{a}}\end{array}$ & $\begin{array}{l}E_{\mathrm{g}}{ }^{\text {opt }} \\
(\mathrm{eV})^{\mathrm{b}}\end{array}$ & $\begin{array}{l}\text { HOMO } \\
(\mathrm{eV})^{\mathrm{c}}\end{array}$ & $\begin{array}{l}\text { LUMO } \\
(\mathrm{eV})^{\mathrm{c}}\end{array}$ & $\begin{array}{l}E_{\mathrm{g}}^{\mathrm{e}} \\
(\mathrm{eV})^{\mathrm{c}}\end{array}$ \\
\hline PBBT-FT & 1061 & 1.17 & -5.35 & -3.76 & 1.59 \\
PBBT-T-FT & 1221 & 1.02 & -5.05 & -3.74 & 1.31 \\
PBBT-Tz-FT & 1166 & 1.06 & -5.42 & -3.80 & 1.62 \\
\hline
\end{tabular}

a Onset wavelength of the polymer films; b Optical bandgap estimated from the onset wavelength of the polymer films; c Energy levels and bandgaps estimated from the electrochemical measurements. 
The HOMO and LUMO energy levels determined by the electrochemical onset oxidation and onset reduction potentials, respectively, are summarized in Table 1, and the energy level diagram of the BBT-based copolymers together with the donor molecules are shown in Figure 3. All three BBT-based copolymers had similar LUMO energy levels probably because the BBT unit possessed the dominant effect on the LUMOs. In contrast, the HOMO energy levels were undoubtedly varied depending on the $\pi$-conjugated bridges. The $\mathrm{E}_{\text {Hомо }}$ of PBBT-T-FT was located at $-5.05 \mathrm{eV}$, which was by $0.30 \mathrm{eV}$ higher than that of PBBT-FT. However, the $\mathrm{E}_{\text {Hомо }}$ of PBBT-Tz-FT was $-5.42 \mathrm{eV}$ due to the additional electron-accepting thiazole units. Overall, it was shown that the LUMO energy levels of the polymers are mainly determined by the strong electron-accepting BBT unit, whereas the HOMO energy levels can be controlled by molecular design.

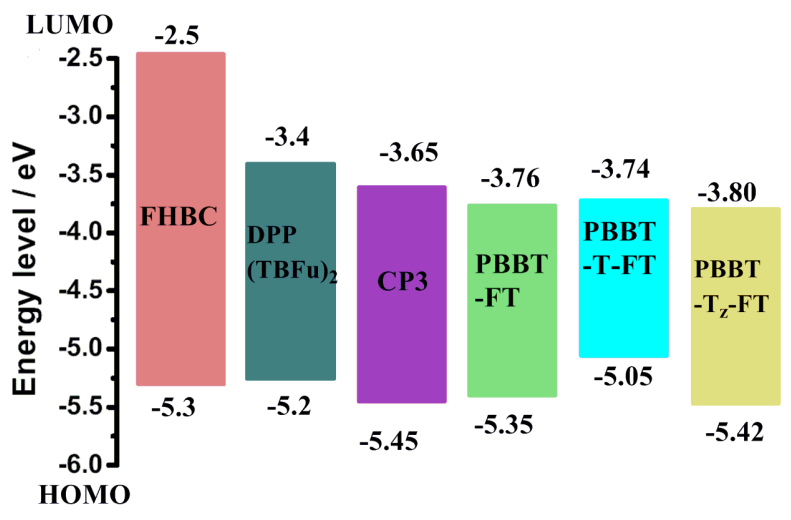

Figure 3. Energy level diagram of the donor molecules and BBT-based copolymers.

\subsection{Photovoltaic characteristics}

The BBT-based copolymers were first examined as p-type semiconductors in BHJ-PSCs. Devices were fabricated on the basis of ITO/PEDOT:PSS/BBT-based copolymer: $\mathrm{PC}_{71} \mathrm{BM} / \mathrm{LiF} / \mathrm{Al} / \mathrm{Ag}$ configuration, and their performances were measured under AM1.5G illumination. The active layers composed of BBT-based copolymer and $\mathrm{PC}_{71} \mathrm{BM}(1: 1 \mathrm{wt} / \mathrm{wt})$ were spin-coated from the 1,2-dichlorobenzene (DCB) solution. The detailed photovoltaic parameters of the devices are shown in Table 2. A preliminary test of the device based on PBBT-FT/PC ${ }_{71} \mathrm{BM}$ (spin-coated from the solution at the concentration of $8 \mathrm{mg} / \mathrm{mL}$ ) suggested the limited power conversion efficiency (PCE) of $0.06 \%$. On the other hand, the devices based on PBBT-T-FT and PBBT-Tz-FT fabricated under the same conditions showed slightly higher PCEs of $0.17 \%$ and $0.11 \%$, respectively. Further experiments were conducted to increase the film thickness of the active layer. It was found that spin-coating from higher concentration solutions results in thicker films. When the device was fabricated from the PBBT-T-FT:PC ${ }_{71} \mathrm{BM}$ solution at $14 \mathrm{mg} / \mathrm{mL}$, the highest PCE of $0.20 \%$ with a $V_{\text {oc }}$ of $0.63 \mathrm{~V}, \mathrm{a} \mathrm{J} \mathrm{J}_{\mathrm{sc}}$ of $0.78 \mathrm{~mA} \mathrm{~cm}^{-2}$, and fill factor (FF) of 40.61 was obtained. A further increase in the active layer thickness, on the contrary, decreased the PCE to $0.16 \%$. Unfortunately, the devices based on PBBT-Tz-FT showed a gradual decease in the PCE with the increasing the film thicknesses.

Next, BBT-based copolymers were applied to n-type semiconductors of BHJ-PCSs due to the low-lying LUMO energy levels (around $-3.8 \mathrm{eV}$ ). Among the list of p-type organic semiconductors, FHBC and DPP(TBFu $)_{2}$ were selected as small molecular donor materials and CP3 as a donor polymer. The device performances were optimized based on the p-,n-semiconductor weight ratio from $2: 1$ to $1: 2$, film thicknesses, and post-treatment, which are summarized in Table 2. In the case of the FHBC donor, the devices based on PBBT-T-FT and PBBT-Tz-FT displayed the better performances than those based on PBBT-FT. The current density-voltage $(\mathrm{J}-\mathrm{V})$ curves of the best devices suggested the significant difference in $\mathrm{J}_{\mathrm{sc}}$ (Figure 4). Interestingly, thermal annealing at $150{ }^{\circ} \mathrm{C}$ for $15 \mathrm{~s}$ resulted in the performance decrease. Accordingly, the best PCE of $0.0236 \%$ was recorded for the device based on FHBC:PBBT-FT $(1: 1 \mathrm{wt} / \mathrm{wt})$. Compared with the polymer:PC ${ }_{71} \mathrm{BM}$

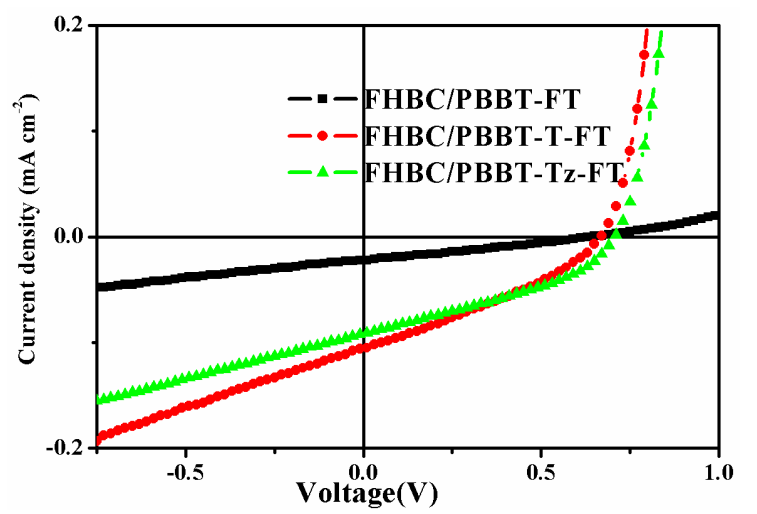

Figure 4. Current density-voltage (J-V) curves of the PSCs based on FHBC:BBT-based copolymer under the illumination of AM1.5G, $100 \mathrm{~mW} \mathrm{~cm}$. 
Table 2. Summary of polymer solar cells performances

\begin{tabular}{|c|c|c|c|c|c|c|c|}
\hline Active layer & Weigt ratio & treatment $^{\mathrm{a}}$ & $\begin{array}{c}\text { Thickness } \\
(\mathrm{nm})^{\mathrm{b}}\end{array}$ & $\mathrm{V}_{\mathrm{oc}}(\mathrm{V})$ & $\begin{array}{c}\mathrm{J}_{\mathrm{sc}} \\
\left(\mathrm{mA} / \mathrm{cm}^{2}\right)\end{array}$ & $\mathrm{FF}$ & PCE $(\%)$ \\
\hline PBBT-FT:PC ${ }_{71}$ BM & $1: 1(8 m g / m L)$ & - & & 0.51 & 0.35 & 33.19 & 0.06 \\
\hline PBBT-T-FT:PC ${ }_{71} \mathrm{BM}$ & $1: 1(8 \mathrm{mg} / \mathrm{mL})$ & - & $44 \pm 4$ & 0.60 & 0.76 & 37.33 & 0.17 \\
\hline PBBT-T-FT:PC ${ }_{71} \mathrm{BM}$ & $1: 1(10 \mathrm{mg} / \mathrm{mL})$ & - & $50 \pm 3$ & 0.58 & 0.79 & 34.81 & 0.16 \\
\hline PBBT-T-FT:PC ${ }_{71} \mathrm{BM}$ & $1: 1(12 \mathrm{mg} / \mathrm{mL})$ & - & $67 \pm 3$ & 0.62 & 0.75 & 40.80 & 0.19 \\
\hline PBBT-T-FT:PC ${ }_{71}$ BM & $1: 1(14 \mathrm{mg} / \mathrm{mL})$ & - & $65 \pm 5$ & 0.63 & 0.78 & 40.61 & 0.20 \\
\hline PBBT-T-FT:PC ${ }_{71} \mathrm{BM}$ & $1: 1(16 \mathrm{mg} / \mathrm{mL})$ & - & $79 \pm 4$ & 0.64 & 0.60 & 40.93 & 0.16 \\
\hline PBBT-Tz-FT:PC ${ }_{71}$ BM & $1: 1(8 \mathrm{mg} / \mathrm{mL})^{\mathrm{c}}$ & - & $82 \pm 5$ & 0.57 & 0.46 & 39.99 & 0.11 \\
\hline PBBT-Tz-FT:PC ${ }_{71} \mathrm{BM}$ & $1: 1(10 \mathrm{mg} / \mathrm{mL})^{\mathrm{c}}$ & - & $90 \pm 11$ & 0.55 & 0.45 & 38.99 & 0.10 \\
\hline PBBT-Tz-FT:PC ${ }_{71} \mathrm{BM}$ & $1: 1(12 \mathrm{mg} / \mathrm{mL})^{\mathrm{c}}$ & - & $123 \pm 5$ & 0.48 & 0.26 & 37.80 & 0.05 \\
\hline PBBT-Tz-FT:PC ${ }_{71} \mathrm{BM}$ & $1: 1(14 \mathrm{mg} / \mathrm{mL})^{\mathrm{c}}$ & - & $139 \pm 4$ & 0.54 & 0.30 & 35.38 & 0.06 \\
\hline PBBT-Tz-FT:PC ${ }_{71} \mathrm{BM}$ & $1: 1(16 \mathrm{mg} / \mathrm{mL})^{\mathrm{c}}$ & - & $164 \pm 17$ & 0.50 & 0.31 & 36.38 & 0.06 \\
\hline FHBC:PBBT-T-FT & $1: 1$ & - & $53 \pm 8$ & 0.67 & 0.11 & 32.36 & 0.0228 \\
\hline FHBC:PBBT-T-FT & $1: 2$ & - & $30 \pm 6$ & 0.46 & 0.10 & 29.63 & 0.0135 \\
\hline FHBC:PBBT-T-FT & $1: 2$ & TA & $42 \pm 4$ & 0.55 & 0.12 & 29.25 & 0.0190 \\
\hline FHBC:PBBT-Tz-FT & $1: 1$ & - & $53 \pm 4$ & 0.71 & 0.09 & 36.32 & 0.0236 \\
\hline FHBC:PBBT-Tz-FT & $1: 1$ & TA & $54 \pm 8$ & 0.60 & 0.09 & 37.38 & 0.0199 \\
\hline FHBC:PBBT-Tz-FT & $1: 2$ & - & $47 \pm 5$ & 0.59 & 0.09 & 37.88 & 0.0206 \\
\hline FHBC:PBBT-Tz-FT & $1: 2$ & TA & $41 \pm 5$ & 0.51 & 0.10 & 38.25 & 0.0186 \\
\hline $\mathrm{DPP}(\mathrm{TBFu})_{2}: \mathrm{PBBT}-\mathrm{Tz}-\mathrm{FT}$ & $1: 1^{\mathrm{d}}$ & - & $123 \pm 14$ & 0.61 & 0.0736 & 36.00 & 0.0160 \\
\hline $\mathrm{DPP}(\mathrm{TBFu})_{2}: \mathrm{PBBT}-\mathrm{Tz}-\mathrm{FT}$ & $2: 1^{\mathrm{d}}$ & - & $175 \pm 19$ & 0.63 & 0.0519 & 38.00 & 0.0123 \\
\hline DPP(TBFu $)_{2}:$ PBBT-Tz-FT & $2: 1^{d}$ & SVA & $173 \pm 19$ & 0.56 & 0.0937 & 32.00 & 0.0166 \\
\hline CP3:PBBT-T-FT & $1: 1$ & VD & $111 \pm 11$ & 0.67 & 0.0640 & 31.00 & 0.0132 \\
\hline CP3:PBBT-T-FT & $1: 1$ & HD & $119 \pm 27$ & 0.61 & 0.0660 & 31.00 & 0.0124 \\
\hline CP3:PBBT-T-FT & $1: 2$ & $\mathrm{HD}$ & $138 \pm 50$ & 0.61 & 0.0636 & 32.00 & 0.0124 \\
\hline
\end{tabular}

${ }^{a} \mathrm{TA}$ : thermal annealing at $150{ }^{\circ} \mathrm{C}$ for $15 \mathrm{~s}$, SVA: solvent vapor annealing using THF, VD: vacuum dried, HD: hot dried. ${ }^{\mathrm{b}}$ Thickness of the active layers determined by a surface prolifimeter. ${ }^{\mathrm{c}}$ Spin-coated at $1200 \mathrm{rpm}$ for $80 \mathrm{~s} .{ }^{\mathrm{d}}$ Spin-coated at $1500 \mathrm{rpm}$ for 30s.

devices, the $\mathrm{J}_{\mathrm{sc}}$ values are much smaller. This might have been caused by the strong aggregation nature of BBT-based copolymers [11]. It is well-known that large semiconductor domains in BHJ films lead to poor phase separation, reduced exciton diffusion/separation efficiencies, and low $\mathrm{J}_{\mathrm{sc}}$ [12].

In addition to FHBC, $\mathrm{DPP}(\mathrm{TBFu})_{2}$ is a high-performance p-type semiconductor in $\mathrm{BHJ}$ solar cells. It was recently reported that solvent annealing is effective for the enhancement of the photovoltaic performances of $\mathrm{DPP}(\mathrm{TBFu})_{2}$-based devices [13]. Thus, the fullerene-free devices were fabricated similar to those of FHBC. However, the performances of most devices unfortunately became lower when solvent (THF vapor) annealing was attempted (Table 2). An exception was the DPP(TBFu $)_{2}:$ PBBT-Tz-FT device $(2: 1 \mathrm{wt} / \mathrm{wt})$, which showed a slight increase in the $\mathrm{J}_{\mathrm{sc}}$ and PCE upon exposure to THF vapor. This increase in the photovoltaic performances is clearly presented in the J-V curves (Figure 5).

Although various spin-coating conditions were examined, the active layers composed of small molecular donors and BBT-based copolymers were thin. In order to produce thicker and homogeneous films, p-type semiconducting polymers are promising donor materials. Therefore, the recently developed new semiconducting polymer of $\mathrm{CP} 3$ was also examined. The devices based on CP3 and BBT-based copolymers are all-polymer solar cells. Accordingly, thicker films (100-500 nm) were successfully obtained by spin-coating the viscous DCB solutions. However, the homogeneity of the films was disappointedly low in the case of PBBT-FT and PBBT-T-FT even after the careful drying treatments. Therefore, the photovoltaic performances of these devices were poor (Table 2). 
Although large-area homogeneous films were obtained from the CP3:PBBT-Tz-FT solutions, they were too thick $(400-500 \mathrm{~nm})$. As the effective diffusion lengths of carriers are usually limited to approximately $100 \mathrm{~nm}$, the $\mathrm{J}_{\mathrm{sc}}$ values of these devices dramatically decreased.

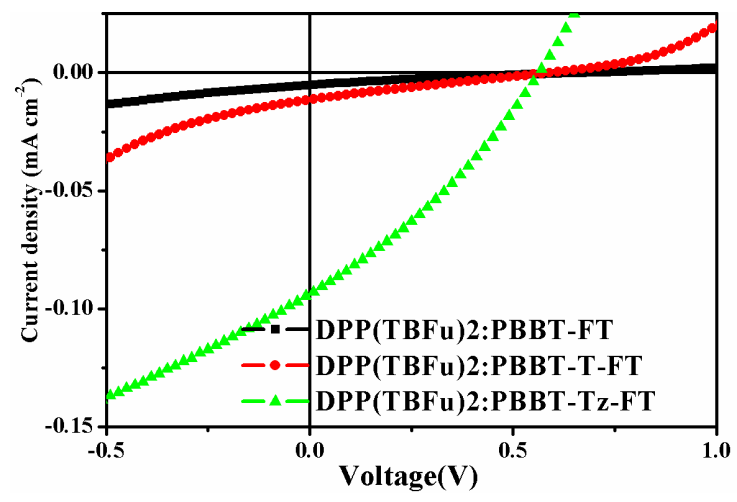

Figure 5. Current density-voltage (J-V) curves of the PSCs based on DPP(TBFu $)_{2}$ :BBT-based copolymer under the illumination of AM1.5G, $100 \mathrm{~mW} \mathrm{~cm}^{-2}$.

\section{Conclusion}

BHJ-PCS performances of BBT-based copolymers were described. The PCE of $0.20 \%$ was obtained when BBT-based copolymers were employed as p-type semiconductors and combined with $\mathrm{PC}_{71} \mathrm{BM}$. However, fullerene-free PSCs based on the BBT-based copolymers used an n-type semiconductors showed much lower PCEs. The best PCE of $0.0236 \%$ was eventually recorded for the device based on FHBC and PBBT-Tz-FT. This result was reasonable because PBBT-Tz-FT was the potent n-type semiconductor with the lowest LUMO energy level among the three PBBT-based copolymers. On the other hand, PBBT-T-FT with the shallower LUMO energy level often exhibited the performances comparable to those of PBBT-Tz-FT. This might be due to the advantageous polymer orientation on the substrate, because the previous OFET study revealed that PBBT-T-FT favors face-on orientation in thin films.

\section{Acknowledgements}

This work was supported by the Tokuyama Science Foundation, the General Sekiyu R\&D Encouragement Assistance Foundation, and the Support for Tokyotech Advanced Researchers (TM). WWHW is supported by an Australian Research Council
Future Fellowship (FT130100500). The numerical calculations were carried out on the TSUBAME2.5 supercomputer at the Tokyo Institute of Technology, Tokyo, Japan, and on the supercomputer at the Research Center for Computational Science, Okazaki, Japan.

\section{References}

1. (a) R. Sondergaard, M. Hosel, D. Angmo, T. T. Larsen-Olsen, F. C. Krebs, Mater. Today, 15 (2012) 36; (b) Y. W. Su, S. C. Lan, K. H. Wei, Mater. Today, 15 (2012) 554.

2. (a) Z. He, C. Zhong, S. Su, M. Xu, H. Wu, Y. Cao, Nat. Photon., 6 (2012) 591; (b) J. B. You, L. T. Dou, K. Yoshimura, T. Kato, K. Ohya, T. Moriarty, K. Emery, C. C. Chen, J. Gao, G. Li, Y. Yang, Nat. Commun., 4 (2013) 1446; (c) W.-H. Chang, L. Meng, L. Dou, J. You, C.-C. Chen, Y. Yang, E. P. Young, G. Li, Y. Yang, Macromolecules, 48 (2015) 562.

3. (a) Y. Lin, Y. Li, X. Zhan, Chem. Soc. Rev., 41 (2012) 4245; (b) Y. Lin, X. Zhan, Mater. Horiz., 1 (2014) 470; (c) X. Guo, A. Facchetti, T. J. Marks, Chem. Rev., 114 (2014) 8943.

4. (a) R. Shivanna, S. Shoaee, S. Dimitrov, S. K. Kandappa, S. Rajaram, J. R. Durrant, K. S. Narayan, Energy Environ. Sci., 7 (2014) 435; (b) X. Zhang, Z. Lu, L. Ye, C. Zhan, J. Hou, S. Zhang, B. Jiang, Y. Zhao, J. Huang, S. Zhang, Y. Liu, Q. Shi, Y. Liu, J. Yao, Adv. Mater., 25 (2013) 5791; (c) Y. Zang, C.-Z. Li, C.-C. Chueh, S. T. Williams, W. Jiang, Z.-H. Wang, J.-S. Yu, A. K.-Y. Jen, $A d v$. Mater., 26 (2014) 5708; (d) D. Mori, H. Benten, I. Okada, H. Ohkita, S. Ito, Energy Environ. Sci., 7 (2014) 2939; (e) Y. Lin, J. Wang, Z.-G. Zhang, H. Bai, Y. F. Li, D. B. Zhu, X. W. Zhan, Adv. Mater., 27 (2015) 1170.

5. (a) K. Ono, S. Tanaka, Y. Yamashita, Angew. Chem. Int. Ed., 33 (1994) 1977; (b) J. D. Yuen, R. Kumar, D. Zakhidov, J. Seifter, B. Lim, A. J. Heeger, F. Wudl, Adv. Mater., 23 (2011) 3780; (c) J. Fan, J. D. Yuen, M. Wang, J. Seifter, J.-H. Seo, A. R. Mohebbi, D. Zakhidov, A. Heeger, F. Wudl, $A d v$. Mater., 24 (2012) 2186; (d) J. Fan, J. D. Yuen, W. Cui, J. Seifter, A. R. Mohebbi, M. Wang, H. Zhou, A. J. Heeger, F. Wudl, Adv. Mater., 24 (2012) 6164; (e) J. D. Yuen, J. Fan, J. Seifter, B. Lim, R. Hufschmid, A. J. Heeger, F. Wudl, J. Am. Chem. Soc., 133 (2011) 20799.

6. (a) E. Bundgaard, F. C. Krebs, Solar Energy Mater. Solar Cells, 91 (2007) 1019; (b) M. L. Keshtov, D. V. Marochkin, V. S. Kochurov, A. R. Khokhlov, E. N. Koukarascd, G. D. Sharma, J. 
Mater. Chem. A, 2 (2014) 155; (c) T. L. D. Tam, T. Salim, H. Li, F. Zhou, S. G. Mhaisalkar, H. Su, Y. M. Lam, A. C. Grimsdale, J. Mater. Chem., 22 (2012) 18528.

7. W. W. H. Wong, T. B. Singh, D. Vak, W. Pisula, C. Yan, X. Feng, E. L. Williams, K. L. Chan, Q. Mao, D. J. Jones, C.-Q. Ma, K. Müllen, P. Bäuerle, A. B. Holmes, Adv. Funct. Mater., 20 (2010) 927.

8. B. Walker, A. B. Tomayo, X. D. Dang, P. Zalar, J. H. Seo, A. Garcia, M. Tantiwiwat, T. Q. Nguyen, Adv. Funct. Mater., 19 (2009) 3063.

9. J. Subbiah, B. Purushothaman, M. Chen, T. Qin, M. Gao, D. Vak, F. H. Scholes, X. Chen, S. E.
Watkins, G. J. Wilson, A. B. Holmes, W. W. H. Wong, D. J. Jones, Adv. Mater., 27 (2015) 702.

10. Y. Wang, T. Kadoya, L. Wang, T. Hayakawa, M. Tokita, T. Mori, T. Michinobu, J. Mater. Chem. C, 3 (2015) 1196.

11. X. Zhan, A. Facchetti, S. Barlow, T. J. Marks, M. A. Ratner, M. R. Wasielewski, S. R. Marder, Adv. Mater., 23 (2011) 268.

12. Y. Huang, E. J. Kramer, A. J. Heeger, G. C. Bazan, Chem. Rev., 114 (2014) 7006.

13. K. Sun, Z. Xiao, E. Hanssen, M. F. G. Klein, H. H. Dam, M. Pfaff, D. Gerthsen, W. W. H. Wong, D. J. Jones, J. Mater. Chem. A, 2 (2014) 9048. 